\title{
Rat Small Intestine Muscle Relaxation Alkaloids from Orixa japonica Leaves
}

\author{
Shinji Funayama, ${ }^{* a}$ Rioko Tanaka, ${ }^{a}$ Yasuhiro Kumekawa, ${ }^{a}$ Toshiro Noshita,${ }^{a}$ Tetsuya Mori, ${ }^{a}$ \\ Tadashi Kashiwagura, ${ }^{a}$ and Kiyoshi Murata ${ }^{b}$ \\ Department of Bioscience and Biotechnology, Aomori University, ${ }^{a}$ 2-3-1 Kohbata, Aomori 030-0943, Japan and Aoba \\ Kasei Co., Ltd., ${ }^{b}$ 4-19-1 Ake-Dori, Sendai 981-3206, Japan. Received June 8, 2000; accepted September 23, 2000
}

Two quinoline alkaloids, japonine (1) and eduline (2) were isolated from the methanol extract of the leaves of Orixa japonica as relaxants against rat small intestine muscle. The activity of these alkaloids was comparable to that of the typical muscle relaxant papaverine (4). This is also the first report of the isolation of eduline (2) from $O$. japonica.

Key words Orixa japonica; quinoline alkaloid; japonine; eduline; rat small intestine; relaxant effect

Orixa japonica (Rutaceae) is a shrub widely distributed in Japan, Korea and China. The stems and leaves of this plant were formerly used in Japan as an insecticide for livestock, and this plant is regarded as one of the materials of the crude drug "Johzan."

In connection with our interest in naturally occurring biologically active compounds of crude drug origin, two quinoline alkaloids, japonine (1) and eduline (2) were isolated from the extract of the leaves of $O$. japonica, and it was found that alkaloids $\mathbf{1}$ and $\mathbf{2}$ showed strong relaxant activity against the small intestine muscle. This report is concerned with the isolation, identification and biological characterization of 1 and 2. ${ }^{1)}$

To date, the following 20 quinoline alkaloids were isolated from various parts of $O$. japonica, from the stems, $(+)$-orixine $(3),{ }^{2,3)} O$-methylbalfourodinium salt, orixinone, ${ }^{4)}(-)$ preorixine, ${ }^{5,6)}$ pteleprenine, isopteleprenine, $N$-demethyllunidonine, $N$-methylflindersine, 8-methoxy- $N$-methylflindersine, (+)-isoptelefolidine, ${ }^{7)} \mathrm{N}$-methylatanine, 8-O-methylglycosolone, 4-O-methylhydroxyluninium chloride ${ }^{8)}$ and $(+)-3^{\prime}-$ $O$-acetylisopteleflorine, ${ }^{9)}$ from the roots, $(+)$-orixine, ${ }^{3)}$ nororixine ${ }^{10)}$ evolitorine, ${ }^{10)}$ kokusagine ${ }^{2)}$ and skimmianine, ${ }^{3)}$ from the leaves, evoxine ${ }^{11)}$ and japonine, ${ }^{12)}$ and from the fruits, kokusaginine and skimmianine. ${ }^{13)}$

This is the first isolation of eduline (2) from Orixa japonica.

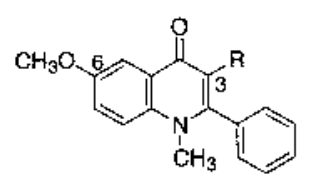

1: $\mathrm{R}=\mathrm{OCH}_{3}$ $2: \mathrm{R}=\mathrm{H}$<smiles>COc1ccc(Cc2nccc3cc(OC)c(OC)cc23)cc1OC</smiles>

\section{MATERIALS AND METHODS}

General Experimental Procedures IR spectra were recorded on a JASCO A-100S spectrometer in $\mathrm{KBr}$ discs. UV spectra were taken on a Hitachi U-3200 spectrophotometer. Mass spectra and high-resolution EI-MS were taken on JEOL JMX DX-303 and/or AX-500 mass spectrometers using a direct inlet system. ${ }^{1} \mathrm{H}-\mathrm{NMR}(300 \mathrm{MHz})$ and ${ }^{13} \mathrm{C}$ NMR (75.5 MHz) spectra were measured by Hitachi R-3000 and Varian Gemini 2000 spectrometers with tetramethylsilane as an internal standard, and chemical shifts were recorded in $\delta$ units. Wakogel C-200 (Wako Pure Chemical Ind., Ltd.) and ICN Alumina N, Akt. I (ICN Biomedicals) were used for column chromatography. DC-Fertigplatten Kieselgel $60 \mathrm{~F}_{254}(0.25 \mathrm{~mm}$ thick, Merck $)$ was used for preparative TLC. DC-Alufolien Kieselgel $60 \mathrm{~F}_{254}(0.2 \mathrm{~mm}$ thick, Merck) was used for TLC analyses.

Plant Material Orixa japonica was collected near Sendai, Japan, in May, 1991 and cut and dried prior to extraction. The plant was identified by one of us (S.F.), and a voucher specimen is deposited in the herbarium of the Department of Bioscience and Biotechnology, Aomori University.

Measurement of Rat Jejunum Smooth Muscle Relaxant Activity The jejunum was isolated from $48 \mathrm{~h}$-starved male rats of the Wistar strain, weighing $180-220 \mathrm{~g}$. The relaxant activity was measured as described previously. ${ }^{14}$ ) Thus, $2 \mathrm{~cm}$ length at both ends of the isolated intestine were tied to the bottle edge with silk thread. The small intestine was immersed in $20 \mathrm{ml}$ of a solution consisting of (in $\mathrm{mM}$ ) $149.1 \mathrm{Na}^{+}, 2.7 \mathrm{~K}^{+}, 1.1 \mathrm{Mg}^{2+}, 1.8 \mathrm{Ca}^{2+}, 143.1 \mathrm{Cl}^{-}, 11.9$ $\mathrm{HCO}_{3}^{-}, 0.4 \mathrm{H}_{2} \mathrm{PO}_{4}^{-}$and 5.6 glucose $(\mathrm{pH} 7.4 \pm 0.1)$ in a bath. The solution was stirred by bubbling it with air. The edge of the intestine was hooked to a strain transducer by a wire, and the signal from the transducer was amplified and recorded (Nihon Kohden isometric transducer TB-651T and isometric amplifier EF-601G). All experiments were done at $37^{\circ} \mathrm{C}$.

Isolation of Japonine (1) and Eduline (2) The dried leaves of $O$. japonica $(3.8 \mathrm{~kg})$ were extracted three times (each $24 \mathrm{~h}$ ) with $n$-hexane and $\mathrm{MeOH}$ at r.t., successively. After filtration, the solvent was evaporated under reduced pressure to afford $n$-hexane $(59 \mathrm{~g})$ and $\mathrm{MeOH}$ extracts (1065 g).

The $\mathrm{MeOH}$ extract was suspended in $\mathrm{H}_{2} \mathrm{O}$ (2.251) and the 


\section{a}

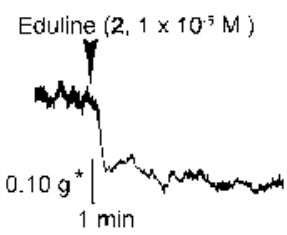

b
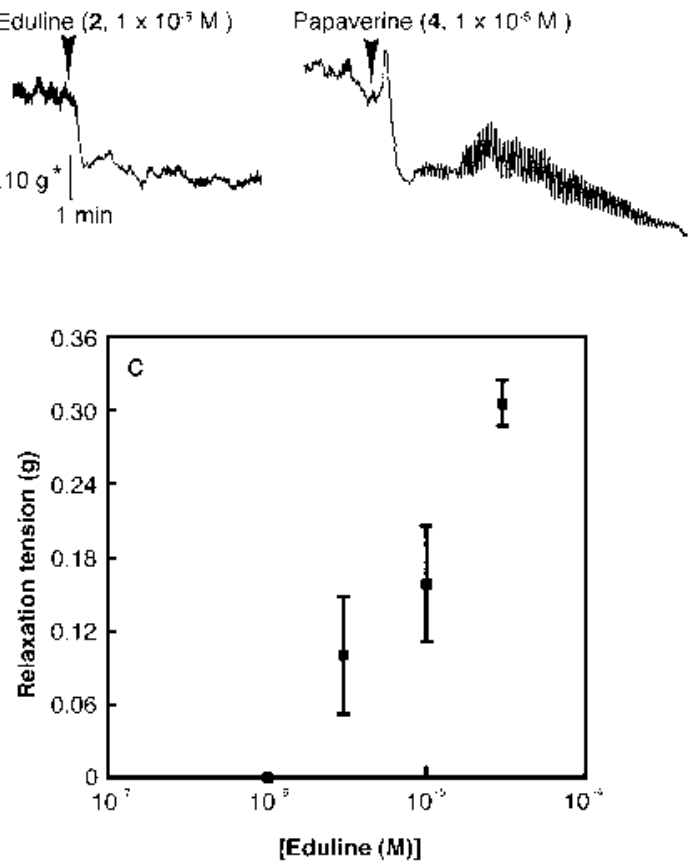

Fig. 1. Rat Jejunum Smooth Muscle Relaxant Activity

Experimental procedures were described in MATERIALS AND METHODS Typical responses of eduline (a) $\left(2,1 \times 10^{-5} \mathrm{M}\right)$ and papaverine (b) $\left(4,1 \times 10^{-5} \mathrm{M}\right)$ are presented The dose-response curve of eduline is also shown (c). Points and bars are mean \pm S.D. for three experiments. *Scale bar of relaxation tension.

Table 1. Effects of Japonine (1) and Eduline (2) Isolated from Orixa japonica Leaves, Orixine (3) and Papaverine (4) on Relaxant Activity of Rat Jejunum

\begin{tabular}{|c|c|c|}
\hline Compounds & $\begin{array}{l}\text { Final Concentration } \\
\qquad(\mu \mathrm{M})\end{array}$ & $\begin{array}{c}\text { Relaxative Tension } \\
\text { (g) }\end{array}$ \\
\hline Japonine (1) & 5 & $0.12 \pm 0.03 \quad(n=2)$ \\
\hline Eduline (2) & 10 & $0.17 \pm 0.05 \quad(n=3)$ \\
\hline Orixine (3) & 10 & $0 \quad(n=3)$ \\
\hline Papaverine (4) & 10 & $0.16 \pm 0.03(n=10)$ \\
\hline
\end{tabular}

suspension was extracted with $\mathrm{CHCl}_{3}$ (2 1) to give $\mathrm{CHCl}_{3}$ solubles $(214 \mathrm{~g})$. The aq. layer was further extracted with EtOAc to give EtOAc solubles $(5 \mathrm{~g})$ and a residue $(776 \mathrm{~g})$. A part of the $\mathrm{CHCl}_{3}$ soluble fraction $(41.9 \mathrm{~g})$ was chromatographed over Wakogel and eluted with $\mathrm{CH}_{2} \mathrm{Cl}_{2}, \mathrm{CH}_{2} \mathrm{Cl}_{2} / \mathrm{MeOH}$ with an increasing concentration of $\mathrm{MeOH}$ to give Fr. II $(1.5 \mathrm{~g}$ : this fraction was eluted with $\left.\mathrm{CH}_{2} \mathrm{Cl}_{2}-\mathrm{MeOH}(20: 1)\right)$ which contained alkaloids $\mathbf{1}$ and $\mathbf{2}$, as well as the preceding Fr. I $(15.0 \mathrm{~g})$ and following Fr. III $(10.1 \mathrm{~g})$. Fr. II (1.5 g) was further chromatographed over silica gel and eluted with $n$ hexane/EtOAc $(1: 1)$ to give Fr. II-1 $(850 \mathrm{mg})$, Fr. II-2 (203 mg), and Fr. II-3 (371 mg).

Fraction II-2 was purified by p-TLC using benzene-EtOAc $(1: 1)$ as a solvent to give japonine $(1,42.5 \mathrm{mg}, 0.0057 \%$ yield) as a colorless powder. $R f=0.17$ (benzene/EtOAc $(1: 1))$. UV $\lambda_{\max }(\mathrm{MeOH}) \mathrm{nm}\left(\varepsilon_{\max }\right): 251$ (34500), 341 (10700), 358 (10400). IR (KBr) cm $\mathrm{cm}^{-1}: 3564,3350,1594$, 1569, 1490, 1316, 1239, 1210, 1121, 1029. EIMS $\mathrm{m} / \mathrm{z} 295$ $\left(\mathrm{M}^{+}, \mathrm{C}_{18} \mathrm{H}_{17} \mathrm{NO}_{3}\right.$, base $), 276,264,252,235,221,207,173$, 140. ${ }^{1} \mathrm{H}-\mathrm{NMR}\left(\mathrm{CDCl}_{3}\right.$, GEMINI 2000$) \delta: 3.53(3 \mathrm{H}, \mathrm{s}$, $\left.N-\mathrm{CH}_{3}\right), 3.66\left(3 \mathrm{H}, \mathrm{s}, \mathrm{C}_{3}-\mathrm{OCH}_{3}\right), 3.97\left(3 \mathrm{H}, \mathrm{s}, \mathrm{C}_{6}-\mathrm{OCH}_{3}\right)$, 7.32 (1H, dd, $J=3,9 \mathrm{~Hz}, \mathrm{H}-7), 7.35-7.41$ (2H, m, arom.),
7.49 (1H, d, $J=9 \mathrm{~Hz}, \mathrm{H}-8), 7.51-7.59$ (3H, m, arom.), 7.97 $(1 \mathrm{H}, \mathrm{d}, J=3 \mathrm{~Hz}, \mathrm{H}-5)$.

Fraction II-3 was chromatographed over Wakogel using $n$ hexane-EtOAc $(1: 1)$ as a solvent to give Fr. III-1 (114 mg), Fr. III-2 (150 mg), and Fr. III-3 (105 mg). Fraction III-2 was further purified by column chromatography over Wakogel using $\mathrm{CHCl}_{3}$ as a solvent to give eduline (2, 72.6 mg, $0.0098 \%$ yield) as a colorless powder. $R f=0.15$ (benzene/ EtOAc (1:1)). UV $\lambda_{\max }(\mathrm{MeOH}) \mathrm{nm}\left(\varepsilon_{\max }\right): 254$ (28700), 337 (9600), 350 (9600). IR (KBr) cm $\mathrm{cm}^{-1}: 3450,1595,1560$, 1482, 1309, 1251, 1228, 1033. EIMS m/z: $265\left(\mathrm{M}^{+}\right.$, $\mathrm{C}_{17} \mathrm{H}_{15} \mathrm{NO}_{2}$, base), 250, 235, 222, 207, 194, 148. HREIMS $m / z$ : $265.1134\left(\mathrm{M}^{+}\right)$; Calcd for $\mathrm{C}_{17} \mathrm{H}_{15} \mathrm{NO}_{2}$; 265.1183. ${ }^{1} \mathrm{H}-$ NMR $\left(\mathrm{CDCl}_{3}, \mathrm{R}-3000\right) \delta: 3.62\left(3 \mathrm{H}, \mathrm{s}, N-\mathrm{CH}_{3}\right), 3.96(3 \mathrm{H}, \mathrm{s}$, $\left.\mathrm{C}_{6}-\mathrm{OCH}_{3}\right), 6.30(1 \mathrm{H}, \mathrm{s}, \mathrm{H}-3), 7.34(1 \mathrm{H}, \mathrm{dd}, J=3,9 \mathrm{~Hz}, \mathrm{H}-7)$, $7.38-7.49$ (2H, m, arom.), $7.48-7.53$ (3H, m, arom.), 7.52 $(1 \mathrm{H}, \mathrm{d}, J=9 \mathrm{~Hz}, \mathrm{H}-8), 7.92(1 \mathrm{H}, \mathrm{d}, J=3 \mathrm{~Hz}, \mathrm{H}-5) .{ }^{13} \mathrm{C}-\mathrm{NMR}$ $\left(\mathrm{CDCl}_{3}, \mathrm{R}-3000\right) \delta: 37.3,55.8,105.7,111.6,117.7,122.8$, $127.9,128.6,128.7,129.5,135.8,136.5,153.8,156.2,176.8$.

Synthesis of Eduline (2) To a stirred solution of diisopropylamine $(1.0 \mathrm{~g}, 10.0 \mathrm{mmol})$ in THF $(30 \mathrm{ml})$, was added dropwise a $1.56 \mathrm{M}$ solution of $n$-BuLi in hexane $(6.4 \mathrm{ml}$, $10.0 \mathrm{mmol})$ at $-30^{\circ} \mathrm{C}$ under argon. The mixture was stirred for $30 \mathrm{~min}$. The solution was cooled to $-70^{\circ} \mathrm{C}$, acetophenone $(300 \mathrm{mg}, 2.0 \mathrm{mmol})$ was added to the solution, and the mixture was stirred for $1 \mathrm{~h}$ at $-70^{\circ} \mathrm{C}$. The suspension of 6methoxy-1-methylisatoic anhydride $\left.{ }^{15}\right)(210 \mathrm{mg}, 1.0 \mathrm{mmol})$ was then added to the solution, and the mixture was stirred for $1.5 \mathrm{~h}$ at $-65^{\circ} \mathrm{C}$. The temperature of the reaction mixture was then gradually raised to room temperature, the mixture was stirred for $12 \mathrm{~h}$, and the reaction was quenched with $\mathrm{AcOH}$. The reaction mixture was extracted with $\mathrm{CH}_{2} \mathrm{Cl}_{2}$, the extract being washed with water and brine, and then dried over $\mathrm{CaCl}_{2}$. Evaporation of the extract and purification of the residue by recrystallization gave eduline $(1,103.5 \mathrm{mg}, 0.4$ mmol, $40 \%$ ). The ${ }^{1} \mathrm{H}-\mathrm{NMR}$ data and $R f$ value of synthesized eduline (1) were fully identical with those of the isolated material.

\section{RESULTS AND DISCUSSION}

Isolation and Identification of Japonine (1) and Eduline (2) The $\mathrm{MeOH}$ of Orixa japonica extract was suspended in $\mathrm{H}_{2} \mathrm{O}$, and the suspension was extracted with $\mathrm{CHCl}_{3}$ and EtOAc, successively, to give a biologically active $\mathrm{CHCl}_{3}$ soluble fraction which was further chromatographed over silica gel and monitored by the biological activity test described above to give japonine (1) and eduline (2).

Alkaloid 1 showed $m / z 295\left(\mathrm{M}^{+}\right)$in the EIMS, and in the ${ }^{1} \mathrm{H}-\mathrm{NMR}$ spectrum of this alkaloid, three aromatic signals at $\delta 7.32(1 \mathrm{H}, \mathrm{dd}, J=3,9 \mathrm{~Hz}, \mathrm{H}-7), 7.49(1 \mathrm{H}, \mathrm{d}, J=9 \mathrm{~Hz}, \mathrm{H}-8)$ and $7.97(1 \mathrm{H}, \mathrm{d}, J=3 \mathrm{~Hz}, \mathrm{H}-5)$ were coupled with each other, and three $O-$ and/or $N-$ Me signals at $\delta 3.53\left(3 \mathrm{H}, \mathrm{s}, N-\mathrm{CH}_{3}\right)$, $3.66\left(3 \mathrm{H}, \mathrm{s}, \mathrm{O}-\mathrm{CH}_{3}\right)$ and $3.97\left(3 \mathrm{H}, \mathrm{s}, \mathrm{O}-\mathrm{CH}_{3}\right)$ were observed, together with five aromatic signals at $\delta 7.35-7.41(2 \mathrm{H}, \mathrm{m})$ and $7.51-7.59(3 \mathrm{H}, \mathrm{m})$, which was assigned to a $\mathrm{C}_{6} \mathrm{H}_{5}$-moiety. These data suggested this alkaloid to be japonine (1) formerly isolated from this plant. ${ }^{12)}$ The identification was accomplished by comparison of the spectral data of the isolate with those reported.

Alkaloid 2 showed a similar UV spectrum to that of $\mathbf{1}$. In 
the HREIMS of 2, an ion at $m / z 265.1134\left(\mathrm{M}^{+}\right)$was observed, and the molecular formula of this alkaloid was elucidated as $\mathrm{C}_{17} \mathrm{H}_{15} \mathrm{NO}_{2}$ (Calcd 265.1183). In the ${ }^{1} \mathrm{H}-\mathrm{NMR}$ spectrum of alkaloid 2, three aromatic signals at $\delta 7.34(1 \mathrm{H}$, dd, $J=3,9 \mathrm{~Hz}, \mathrm{H}-7), 7.52(1 \mathrm{H}, \mathrm{d}, J=9 \mathrm{~Hz}, \mathrm{H}-8)$ and $7.92(1 \mathrm{H}, \mathrm{d}$, $J=3 \mathrm{~Hz}, \mathrm{H}-5$ ) were coupled with each other, and a set of five aromatic signals at $\delta 7.38-7.49(2 \mathrm{H}, \mathrm{m}$, arom.) and 7.48$7.53\left(3 \mathrm{H}, \mathrm{m}\right.$, arom.) attributed to a $\mathrm{C}_{6} \mathrm{H}_{5}$-moiety, as in the case of alkaloid 1, were observed. On the other hand, only two $O-$ and/or $N-$ Me signals at $\delta 3.62$ and 3.96 (each $3 \mathrm{H}, \mathrm{s}$ ), were observed. Instead, one proton singlet at $\delta 6.30(1 \mathrm{H}, \mathrm{s})$ was observed. From all of the data described above, this alkaloid was estimated to be attributed to eduline (2), ${ }^{16)}$ and 2 was synthesized in 4 steps starting from 5-methoxy-2-nitrobenzoic acid according to Coppola. ${ }^{15)}$ The ${ }^{1} \mathrm{H}-\mathrm{NMR}$ spectroscopic features and $R f$ value of synthesized eduline (1) were fully identical with those of the isolated material. Because $\delta 3.96(3 \mathrm{H}, \mathrm{s})$ was assigned to $\mathrm{C}_{6}-\mathrm{O}-\mathrm{CH}_{3}$ in eduline (2), it was elucidated that $\delta 3.97(3 \mathrm{H}, \mathrm{s})$ of japonine (1) was assigned to the $\mathrm{C}_{6}-O-\mathrm{CH}_{3}$ and $\delta 3.66(3 \mathrm{H}$, s) of 1 was assigned to $\mathrm{C}_{3}-\mathrm{O}-\mathrm{CH}_{3}$, respectively. Eduline (2) was formerly isolated from the seeds of Casimiroa edulis (Rutaceae), ${ }^{16}$ ) whereas this is the first isolation of this compound from Orixa japonica.

The relaxation activity of the rat jejunum smooth muscle by the alkaloids extracted from Orixa japonica leaves was examined in the bath solution. ${ }^{14)}$ Thus, the addition of $5 \mu \mathrm{M}$ japonine (1) and $10 \mu \mathrm{M}$ eduline (2) to the bath solution caused relaxation of the intestine. No phasic relaxation effect was observed; typical responses of eduline (2) and papaverine (4) are shown in Figs. 1-a and 1-b. The first relaxation was acute and then the response decreased progressively with time. The maximal response was mostly observed around 3 min after the addition of alkaloids to the bath solution, and the response was measured for about $5 \mathrm{~min}$. The dose-response curve of eduline (2) is also shown in Fig. 1-c.

Table 1 shows the parameters of dose-response curves for the relaxation induced by japonine (1) and eduline (2) extracted from Orixa japonica leaves, and orixine (3) isolated from the stem of the same plant. As depicted in this table, al- kaloids $\mathbf{1}$ and $\mathbf{2}$ showed similar potency concerned with the relaxant effect in rat jejunum smooth muscle, whereas orixine (3) did not show such activity. This is the first report of the rat small intestine relaxative activity of alkaloids $\mathbf{1}$ and $\mathbf{2}$, and it is noteworthy that such activity of these compounds $(0.12 \pm 0.03 \mathrm{~g}$ and $0.17 \pm 0.05 \mathrm{~g}$, respectively) were equal to that of papaverine $(4,0.16 \pm 0.03 \mathrm{~g})$ (Table 1$)$.

Acknowledgements The authors thank Messrs. Hideki Hayasaka and Keiji Ohba, Medicinal Plant Garden of Tohoku University, for collecting the plant material, and the analytical center of the Faculty of Pharmaceutical Sciences, Tohoku University is acknowledged for the EI-MS data. We appreciate Professor Geoffrey A. Cordell, Department of Medicinal Chemistry and Pharmacognosy, College of Pharmacy, University of Illinois at Chicago, for his help in reviewing the manuscript prior to submission.

\section{REFERENCES AND NOTES}

1) A part of this work was presented at the 118th Annual Meeting of the Pharmaceutical Society of Japan, Kyoto, April 1998. Abstracts of Papers 2, p. 163.

2) Terasaka M., Yakugaku Zasshi, 51, 707 (1931).

3) Terasaka M., Chem. Pharm. Bull., 8, 523 (1960).

4) Donnelly W. J., Grundon M. F., J. Chem. Soc., Perkin Trans. 1, 1972, 2116.

5) Funayama S., Kageyama T., Murata K., Adachi M., Nozoe S., Heterocycles, 35, 607 (1993).

6) Funayama S., Murata K., Nozoe S., Chem. Pharm. Bull., 44, 1885 (1996).

7) Funayama S., Murata K., Nozoe S., Phytochemistry, 36, 525 (1994).

8) Funayama S., Murata K., Nozoe S., Nat. Med., 50, 182 (1996).

9) Funayama S., Murata K., Nozoe S., Phytochemistry, 41, 1231 (1996).

10) Terasaka M., Narahashi K., Tomikawa Y., Chem. Pharm. Bull., 8, 1142 (1960).

11) Yajima T., Kato N., Munakata K., Agric. Biol. Chem., 41, 1263 (1977).

12) Ke H.-H., Luckner M., Reisch J., Phytochemistry, 9, 2199 (1970).

13) Obata T., Yakugaku Zasshi, 59, 145 (1939).

14) Kashiwagura T., Sakurai K., Takeguchi N., Biochem. Biophys. Acta, 903, 248 (1987).

15) Coppola G. M., J. Heterocyclic Chem., 19, 723 (1982).

16) Dreyer D. L., J. Org. Chem., 33, 2577 (1968). 